\title{
Forty Years of Change
}

\author{
Shirley Horton* \\ Department of Health, UK \\ *Corresponding Author: Shirley Horton, Department of Health, UK.
}

Received: October 21, 2019; Published: November 05, 2019

DOI: 10.31080/ASNH.2019.03.0528

Shirley Horton retired from teaching in 2015 and looks back over the past 40 years of developments in health education in schools and looks to the challenges of the future. During her career she has fulfilled a number of pastoral roles in the three schools she has worked in and has seen and experienced the impact of a wide range of initiatives aimed at guiding students to make informed choices in their own lives.

My own experiences of being on the receiving end of health education at school are very limited. We had regular visits from the school nurse aka Nitty Nora the bug explorer, the school dentist and the dreaded school medical, apart from that I cannot recall any input from the teachers on health issues until I was in the secondary school. Starting puberty and the dreaded periods at nine it seemed junior schools were just not geared up for this and being "special" meant that the two of us who were "grown up" could use the teacher's toilets which led to intense questioning from our fellow pupils.

My parents were not very forthcoming about health issues, this being the time of baths once a week in a tin bath by the fire and filling up on cheaper carbohydrate foods and eating it all up so you could have pudding. Central heating did not exist and suet puddings and dumplings were required for energy and warmth. Short socks were the order of the day and I can still recall the odour of damp wool gloves, scarves and balaclavas drying on the metal cage surrounding the open fire in my infant classroom. Chilblains were another winter complaint which we do not hear about today. Another unpleasant memory was warm school milk which had spent all day on the mantelpiece ready to reward girls and boys who had worked hard, I have never liked warm milk since then, it's much better icy cold straight from the crate on a winter's day. If we were lucky we got the milk before the blue tits pecked the cream off.
From an early age I was actively interested in health issues. My auntie was an infant teacher and I can recall reading books about the health of the school child and looking at textbooks with the importance of outdoor play and PE for development. I was intent on becoming a teacher from an early age and could see that health was important if children were to do well at school. My own attendance at school was not very good having had most of the childhood illnesses quite badly in the junior school and having a period of time with pneumonia. I have always had problems with decimals ever since as I missed the block of lessons where the mysteries and rules were explained.

At Grammar school I followed a very academic curriculum, there was no time for PSHE, the prefects dispensed the discipline out of the classroom and there was bullying and teasing. The teachers seemed very remote sitting in their gowns at high desks, the thought of telling anyone about being unhappy at school or about being bullied just didn't enter my mind. The attitude at home was to stand up for myself, not to allow myself to be put down and to smack someone if necessary! It wasn't until we had a new head of sixth form who was keen on pastoral welfare that I began to blossom. The last two years in the upper school were really happy and as a prefect I took part in a pioneering project to help younger students to settle in to the school and worked in an anti-bullying group. This made me realise that I really did want to be a teacher and I decided to train at Totley Thornbridge College in Sheffield to teach Home Economics. This in itself was a battle as school thought I was underselling myself and should be following a much more academic course. I suppose today we would talk about not reaching my potential!

The course I followed with Health education as an option really set me up for working in schools in the late 1970's. This was 
a period of great change and saw the first of the developments in the teaching of health issues in schools. Poor personal hygiene was an issue in many of the schools I did teaching practice in. Many of the pupils came from homes without an inside bathroom and toilet and the regular changing of clothes and washing of hair was seen as an important part of the Home Economics curriculum. Many rooms still had a "flats experience" area and girls did come and have baths at lunchtime and talk about period problems and concerns. All of the teachers I worked with at this time saw their job as having a strong pastoral role in the welfare of the pupils in their care and they dispensed a lot of tea and sympathy as well as making sure that children had a proper meal as many came to school without breakfast or change to buy some lunch. They were all good listeners and were very perceptive about the true reasons behind some of the health issues. The teaching of sex education was also a new development and I still blush at some of the first lessons I taught on teaching practice. Thinking back, I wasn't much older that some of the pupils and they certainly knew a lot more than I did! We had only done about rabbits, rats and birds at school! Forward thinking schools included this as a topic in the new fifth year for the school leavers. The school leaving age changed in 1972 (*ROSLA) and preparation for adulthood led to new courses about being responsible and parent craft. As you can imagine most teachers were not rushing to teach the subject matter and much of it was left to the Home Economics department, R.E or P.E. Depending who was teaching the course the message varied but in most cases it was don't do this otherwise you will end up pregnant. There was no attempt to explain about contraception and its careful use. Kits showing examples did not exist and despite all you hear about the swinging sixties and seventies the "pill" was not always easy for single women to get. The emotional side of relationships was not explored and choosing carefully and not sleeping around was the main message. V.D* was seen as something that people got as a punishment for being promiscuous. There was little or no discussion about the age of consent or what consent actually meant or respect or negotiation. It was basically a case of "nice girls don't. It is interesting to compare with today where mixed sex groups are empowered in the classroom and prepared for real life by discussing issues and role- playing condom use negotiation situations.

My first job was at a school in Leicestershire. This opened up lots of new challenges for me as a young Home Economics teacher. The school roll seemed to grow on a daily basis as we accepted the children of families fleeing from the purges of Idi Amin in Uganda. In a traditional cookery course there were not many dishes which would adapt easily. Not touching or eating eggs during their menstrual cycle was a particular issue for some of the girls which made making even the simplest of cakes difficult. The provision of vegetarian ingredients was another problem and I can recall worrying that a child had got the wrong fat in the dish they took home for the family to share. The health needs of students were well provided for and there was an emerging PSHE course which I quickly became involved with. The Senior Mistress told me it would be a good career opportunity and soon I was involved in negotiations with religious leaders and families about a new series of lessons on tape called" Living and Growing.". This series of lessons was a big improvement on some of the Scandinavian tapes I had used previously with older pupils, in many of these films orgasm was shown with the couple in the sea or with waves breaking on the beach. I often wonder how many pupils went away thinking that if you bathed in the sea you could get pregnant, as often the next frame showed a pregnant woman at the antenatal class. It was an interesting time for me as a young teacher as I built up my own knowledge of different cultural practices and beliefs about menstruation and F.G.M as well as doing battle with a massive piece of new technology called the video recorder. This was the most frightening piece of kit I had ever used, it was expensive, locked up in a big cabinet and had reel to reel tape system. It was always a relief to me when the lesson ended and the tape rewound and didn't break!

The next twenty years at a secondary school in the Lincolnshire Fens was a very busy time for me personally and saw a massive number of health education initiatives which were exciting and moved towards what we would regard as good health education practise today. I was fortunate to be encouraged to develop close links with our feeder primary schools, the school nurse, social services, the police and the Lincolnshire Health promotion team. The school valued the importance of PSHE and I was lucky to be able to go on courses to supplement my own subject knowledge and to try out new resources in the classroom. As well as sexual health another local issue was the need for more effective drugs education. Much of the early work and publicity relied upon shock tactics and "if you do this you will die". Nowadays we teach youngsters the skills to resist the temptations, to have good self-esteem and to deal with peer pressure. Smoking particularly amongst girls and underage use of alcohol remain big challenges as the cost to the 
N.H.S increases. The importation and dealing of drugs in the local area was a concern as we were served by three ports with links to the continent and there were regular seizures of drugs. During this time I worked with a group of teachers at County level and we undertook to design and make resources for use in school and to organise and run active learning courses for teachers. This was an exciting time for me and I was fortunate to be allowed time out of school to do this. This is an issue that concerns me today as there is so little time in the busy curriculum to develop new courses and to allow inexperienced teachers to go on courses to develop their own subject knowledge so that they approach teaching PSHE with confidence in the classroom.

Working with parents can be both difficult and rewarding. Most parents are very happy to hand over the teaching of sexual issues to teachers that they trust as it saves them from embarrassment and within a well- planned spiral curriculum there is an opportunity to develop a range of approaches to build upon previous knowledge at a time appropriate to the age and maturity of the class. However, some parents do exercise their right to look at resources and to even withdraw their child from lessons. This is often fuelled by inaccurate reporting by the media and in most cases I found that parents who did raise concerns were reassured once they saw what you were going to cover in lessons. One of the most successful ways of getting parents on board with what you wish to cover is by having regular parents Health evenings as part of a "Friends of the School "programme. Drugs is always a good topic to start with as this is perhaps the topic that parents worry about the most. Active evenings where parents try out the activities done by the pupils are always the best as they are hands on and give the opportunity for discussion. Parents often express their surprise about how open students are in their questions forgetting that they would soon jump to conclusions if the questions in the classroom were raised at home. One of my most embarrassing moments occurred as a result of some sessions I had been running in local primary schools on puberty. I was out with my husband in a busy restaurant when a man shouted across the table "I know you". I said perhaps he was mistaken and carried on eating my meal. A few minutes later he "Yes, I do know you, you are the sex lady! Try explaining that one as nearly everyone in the restaurant seemed to turn around and stare at me.
I have always believed that good quality PSHE underpins the whole school and that it is important for governing bodies and Head teachers to find quality time in the curriculum for lessons for every year group. I have been fortunate to work for some excellent management teams who have also shared the vision that health education is vital.

One of my biggest bugbears in education is that schools are always being criticised for not doing things. Most of the people criticising have never been in a school since they were educated themselves and they have little knowledge of the sterling work being done by teachers day to day in the classroom. Every school is different and it is really important to get to know your catchment area and local neighbourhood. Another useful tool, particularly if you are redesigning your PSHE curriculum is to use the confidential surveys developed by Exeter University with your students. These give you a really good picture of your school and the topics that students are needing information on and are a good methods of getting the message over to curriculum leaders. With consultation and a good choice of staff to deliver the lessons a wide range of issues can be covered through subjects like English, Drama and R.E. Good staff who are willing to teach the subject are very important if you are to deliver the topics well. Too many schools use free lessons on the timetable to make up their PSHE team, this is very short sighted as it is so important to have a good team of teachers who feel relaxed talking about and discussing a variety of issues.

Another useful tool for teachers of Health Education are the reports on local authority areas and the health issues. These give you a good picture of the key concerns in the local area and information about initiatives taking place in the local community. By using these you can tailor your curriculum in school and really make a difference. In 2001, I moved to South Derbyshire and had to design a relevant curriculum from scratch. From the reports I discovered that the key issues were Teenage pregnancy, high rates of death from cancer and heart disease and smoking and alcohol issues amongst young people as well as the whole community and Domestic Abuse. This gave me a focus on which to base my curriculum and soon we were involved in local projects which attracted national attention in the press and funding to develop new work through Theatre in Education. Sadly many of these initiatives were subject to Government cuts in recent years. Quality T.I.E performances were a pow- 
erful vehicle to get difficult situations across to pupils and staff. Another interesting project was "Blueprint for Drugs" which paid for high quality training for non- specialist teachers and provided a two year cycle of lessons on drugs related issues.

However, statistics should be used carefully, the media are always keen to jump on teenage pregnancy figures totally disregarding the fact that these include mothers in secure, married and cohabiting relationships up to the age of 19 and many of the new mums are not schoolgirl mums at all! Sadly, funding at national and local level often dries up when you have shown improvements and something else becomes high priority. One of the most frustrating things for me was when we had successfully negotiated the provision of emergency contraception in the local area and a weekly "clinic" held to provide a service for older students to access contraception from the local nursing team the figures reported in the local paper showed a massive downturn. The result being that funding was withdrawn so the facility had to close and the original problems escalated again.

As I look back over the past 40 years, I feel that the teaching of health education teaching so far has only scratched the surface. It is one of the most important subjects in school and still some schools are doing very little to meet the needs of their pupils. Forty years is a very short period of time to effect a massive change in society and there will always be approaches and initiatives that do not work or have the results that were intended.

As I see it, the challenges for teachers of the future are to continue to address the needs of their students and to provide teaching and opportunities for young people to make informed choices for their lives. In the time elapsed since I retired, the media has been full of issues which need to be addressed by a broad and balanced spiral health curriculum. Girls and increasingly boys are dogged by issues to do with self- esteem and eating disorders. Many of these issues are fuelled by the Internet and the various types of Cyberbullying. The cases of Chlamydia are soaring amongst young people and obesity is at crisis level. Young men are still drinking too much alcohol and consuming energy drinks despite all of the measures to counteract underage drinking and more girls are taking up smoking despite the high cost of cigarettes. Vaping using electronic cigarettes is the newest challenge and the use of legal highs remains a problem. Recent increases in County Lines Drugs issues and the exploitation of young people to "work" in the supply of drugs are a major concern. It seems that there is a need for even more health education provision to aid young people in developing the skills to make decisions in their everyday life.

In conclusion, as I look back through this article, I have missed out so many issues that I could have covered which are of equal importance to the ones I have briefly mentioned. As a society there will always be new challenges to face and by nature we are curious and want to take risks. Preparing and guiding young people to meet these challenges head on and to make healthy and appropriate decisions for their future health remains a challenge for the teachers and dare I say it- the parents of the future.

\section{Volume 3 Issue 12 December 2019 \\ (C) All rights are reserved by Shirley Horton.}

